\title{
Comparative study of the intestinal strongylid communities of equidae in the Askania-Nova biosphere reserve, Ukraine
}

\author{
T. A. KUZMINA*1, V. A. KHARCHENKO ${ }^{1}$, N. S. ZVEGINTSOVA ${ }^{2}$ \\ ${ }^{1}$ Department of Parasitology, Institute of Zoology NAS of Ukraine, 15, B. Khmelnitskogo str., Kyiv, 01601, Ukraine; \\ E-mail: taniak@izan.kiev.ua; ${ }^{2}$ Biosphere Reserve “Askania Nova”, vul. Stepova, 13, Khersonska oblast, Askania-
} Nova, 326332, Ukraine

\begin{abstract}
Summary
Comparative studies of the intestinal strongylid communities of 14 ponies, 6 donkeys and 9 zebras from the "Askania-Nova" Biosphere reserve (Ukraine) were carried out after deworming the hosts with aversectin drug. Faecal sampling (200 g each) was performed at $24,36,48,60$, and 72 hours after treatment; all nematodes expelled were collected and identified. Thirty strongylid species from 12 genera were found; 7 species from the Strongylinae and 23 species from Cyathostominae. In ponies 27 species were found (range $8-23$; mean $14 \pm 3.8$ ). In donkeys 23 species were found (range $11-15$; mean $12 \pm 1.3$ ). Cyathostomum tetracanthum a species specific for donkeys was found for the first time in Ukraine. In zebras 17 species were found (range $2-13$; mean $7 \pm 3.6$ ). The results obtained confirmed the specificity of the intestinal strongylid fauna of different equid species grazing on the same pastures in the "Askania-Nova" reserve.
\end{abstract}

Key words: Strongylida; Cyathostominae; ponies; donkeys; zebras; Ukraine

\section{Introduction}

Equidae are parasitized by 66 nematode species from 18 genera of the order Strongylida (Dvojnos \& Kharchenko, 1994; Lichtenfels et al., 1998). The species composition and general structure of the equids' strongylid communities have been studied in many countries worldwide (Ogbourne, 1976; Eydal, 1983; Renemeyer et al., 1984; Mfitilodze \& Hutchinson, 1985; Lyons et al., 1985, 2000; Gawor, 1995; Bucknell et al., 1995, 1996). Such studies were also carried out in Ukraine. However only domestic horses (Equus cabbalus L.) and Przewalski's horses (Equus przewalskii Poljakov) were investigated (Dvojnos \& Kharchenko, 1994). Fragmentary data have also been published on the species composition of strongylid community in donkeys (Kadenatsii, 1957). No data on the strongylid communities in zebras from zoos and natural reserves of Ukraine are available from literature.

The majority of the strongylid nematodes specific to equids are common in various host species (Ogbourne, 1976; Krecek et al., 1989; Dvojnos \& Kharchenko, 1994; Bucknell et al., 1995, 1996). However, there are some differences in the species composition of the intestinal strongylid communities in particular species of equids. Such species as Cylicocyclus triramosus (Yorke \& Macfie, 1920) Chaves, 1930, Triodontophorus burchelli Krecek et al., 1997, T. hartmannae Krecek et al., 1997, Cylicodontophorus reineckei Scialdo-Krecek and Malan, 1984, Cylindropharynx intermedia Theiler, 1923 and Cylicostephanus longiconus Scialdo-Krecek, 1983, have only been found in zebras from Africa (Scialdo-Krecek, 1983; Scialdo-Krecek \& Malan, 1984; Krecek et al., 1987, 1997; Kharchenko et al., 1997). Cyathostomum tetracanthum (Mehlis, 1831) Molin, 1861, in part, Looss, 1900 (Lichtenfels et al., 1998) has mainly been found in donkeys (Eysker \& Pandey, 1989; Dvojnos \& Kharchenko, 1994; Matthee et al., 2000, 2002); Cyathostomum montgomeryi (Boulenger, 1920) K'ung, 1964 has been found in donkeys and zebras, but not in horses (Kharchenko et al., 2001). There are few comparative studies of intestinal strongylid communities from different equid species (Kennedy and Bush, 1992 - in part; Dvojnos and Kharchenko, 1994; Matthee et al., 2004).

Our study was carried out in the "Askania-Nova" Biosphere Reserve where five equid species: Equus przewalski Poljakov, ponies - E. cabbalus L., E. asini L., E. burchelli Gray and E. hemionus Pallas are kept in semi-free conditions. All equid species graze together on large pastures (up to 1500 ha) and have the possibility to share parasites. The intestinal strongylids of the Przewalski's horses and kulans in the "Askania-Nova" have been studied in the early 1990's (Dvojnos et al., 1990, 1992; Dvojnos, Kharchenko, 1994). No studies of the strongylids from ponies, 
donkeys and zebras were conducted.

The aim of our study was to compare species composition and structure of the intestinal strongylid communities in three species of Equus (donkeys, zebras and ponies) inhabiting the same pastures of the "Askania-Nova" Biosphere Reserve.

\section{Material and Methods}

The study was carried out in December 2004 in the "Askania-Nova" Biosphere Reserve in Khersonska oblast of Ukraine ( $46^{\circ} 29^{\prime}$ North and $33^{\circ} 58^{\prime}$ 'East).

Six donkeys (E. asini L.), 9 zebras (E. burchelli Gray) and 14 ponies (E. cabbalus L.) were investigated. All animals were kept at semi-free conditions on large paddocks (from 90 ha to $1500 \mathrm{ha}$ ) during the grazing season (April November). Zebras and donkeys were housed during winter (December - March), while ponies were grazed year-round. All animals harboured strongylid infection and had not been treated with any anthelmintic preparations during at least for four months prior to our study. Faecal egg counts (EPG) were carried out on the day before treatment and 10 days after treatment using the McMaster technique (Herd, 1992).

Animals were treated per os with aversectin drug "Univerm" ( $0.2 \%$ aversectin, PharmBioMed, Russia) at a dose rate of $0.1 \mathrm{mg}$ aversectin per $\mathrm{kg}$ of body weight. Faecal samples of $200 \mathrm{~g}$ each were collected from each animal 24, $36,48,60$ and $72 \mathrm{~h}$ after treatment. All nematodes expelled were collected, fixed in $70^{\circ}$ ethanol, clarified in $80 \%$ phenol-glycerine solution and identified under the light microscope using the published key (Dvojnos \& Kharchenko, 1994). In total, 13,869 specimens of strongylids were collected and identified.

Data summaries and descriptive analyses were calculated using Microsoft ${ }^{\mathrm{TM}}$ Excel. Multivariate community analyses of the strongylid species data were conducted using PRIMER v. 6.0 (Clarke \& Gorley, 2006).

The shape of the occupancy frequency distribution was determined for all strongylid species according to description of Bucknell et al. (1996). The proportion of each species of the strongylid community of each host was calculated as the number of the specimens of the particular species in relation to the total numbers of strongylids found.

\section{Results}

The mean faecal strongyle egg output for the ponies was 598 eggs per gram of faeces (EPG) (range from 425 to 1100), for the donkeys 325 EPG (range $225-550$ ) and for the zebras 337 (range $125-700$ ). No strongyle eggs were found 10 days after treatment.

The number of nematodes expelled by ponies reached a maximum 24 hours after treatment $(46.4 \%)$. Maximal numbers of nematodes expelled by donkeys and zebras were observed 36 hours after treatment $-68 \%$ and $40.2 \%$, respectively. No strongylids were found in ponies', donkey's and zebra's faeces 72 hours after treatment.
The accumulation curves for the ponies, donkeys and zebras reached apparent asymptotes (Fig. 1). As a result, sample sizes were considered adequate for all Equus species examined.

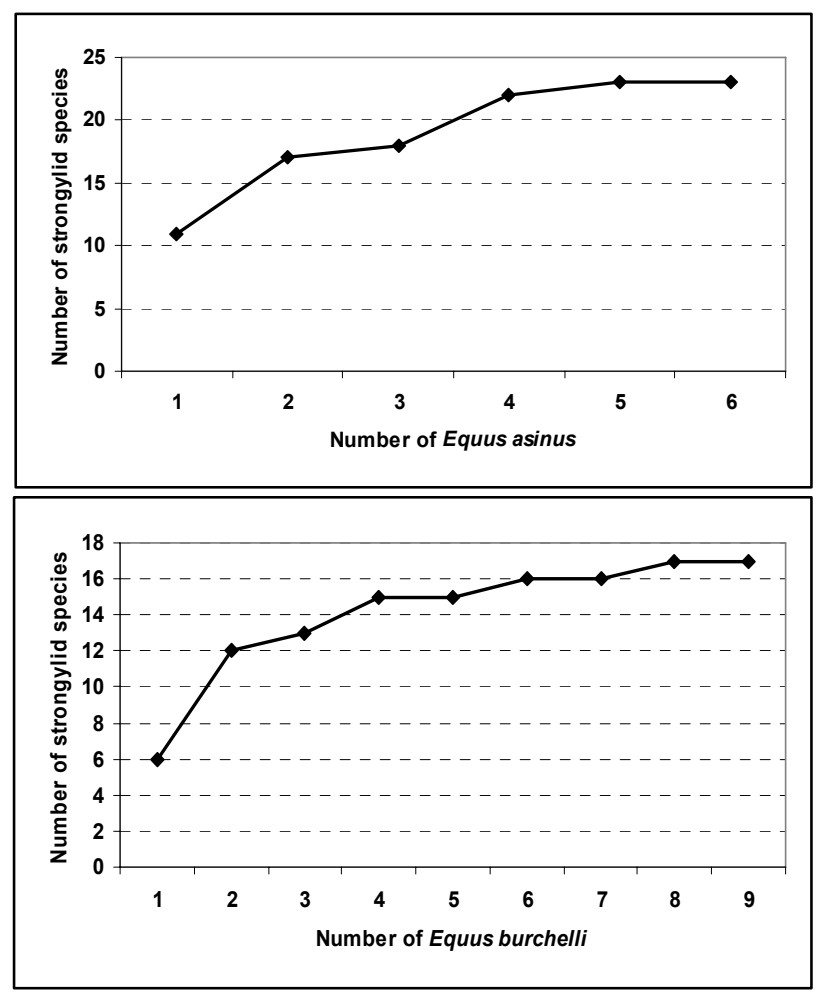

Fig. 1. Accumulation curves of Strongylidae species in 6 donkeys (E. asiunus), 9 zebras (E. burchelli) and 14 ponies (E. caballus) examined

Thirty strongylid species from 12 genera were found, 7 species from the subfamily Strongylinae, and 23 of the Cyathostominae (Table 1).

In ponies 27 species from 11 genera were found (Fig. 2). The number of species per pony ranged from 8 to 23 , a mean $14 \pm 3.8$ (S.D.). Eight species (29.6\% of all species recovered): C. nassatus, C. catinatum, C. goldi, C. leptostomus, C. ashworthi, C. longibursatus, C. minutus and C. calicatus were the dominant in the ponies' strongylid community. Together they composed $92.9 \%$ of the total number of strongylids collected.

In donkey, 23 species from 9 genera were found (range 11 - 15, a mean $12 \pm 1.3$ (S.D.) (Fig. 3). Nine species (34.8\% of all species recovered): C. nassatus, C. leptostomus, C. ashworthi, C. elongatus, C. catinatum, C. pateratus, C. labiatus, C. labratus and C. tetracanthum dominated in the donkeys' strongylid community. Together they composed $93.2 \%$ of the total number of strongylids collected.

The species Cyathostomum tetracanthum (Mehlis, 1831) Molin, 1861, in part, Looss, 1900 (Lichtenfels et al., 1998) was found first in donkeys in Ukraine.

In zebras 17 species from 9 genera were found (range from 3 to 13 , a mean $7 \pm 3.6$ (S.D.) (Fig. 4). Four species (23.5 
Table 1. Nematode species of family Strongylidae Baird, 1856 found in three equid host species in the "Askania Nova" biosphere reserve

\begin{tabular}{|c|c|c|c|c|}
\hline & No./genus & Ponies & Donkeys & Zebras \\
\hline Subfamily Strongylinae & & & & \\
\hline genus Craterostomum & 1 & & & \\
\hline C. acuticaudatum (ACU) & & + & -- & + \\
\hline genus Strongylus & 2 & & & \\
\hline S. vulgaris (SVU) & & + & + & + \\
\hline S. edentatus (SED) & & + & + & -- \\
\hline genus Triodontophorus & 4 & & & \\
\hline T. serratus (TSE) & & + & -- & -- \\
\hline T. nipponicus (TNI) & & + & -- & -- \\
\hline T. tenuicollis (TTE) & & + & -- & -- \\
\hline T. brevicauda (TBR) & & -- & + & -- \\
\hline Subfamily Cyathostominae & & & & \\
\hline $\begin{array}{l}\text { genus Cyathostomum } \\
\text { C catinatum (CAT) }\end{array}$ & 3 & & & \\
\hline $\begin{array}{l}\text { C. catinatum (CAT) } \\
\text { C. tetracanthum (TET) }\end{array}$ & & + & + & + \\
\hline C. tetracanthum (TET) & & -- & + & -- \\
\hline C. pateratus (PAT) & & + & + & + \\
\hline genus Coronocyclus & 3 & & & \\
\hline C. coronatus (COR) & & + & + & -- \\
\hline C. labiatus (LAB) & & + & + & + \\
\hline C. labratus (LBR) & & + & + & + \\
\hline genus Cylicostephanus & 4 & & & \\
\hline C. calicatus (CAL) & & + & + & -- \\
\hline C. minutus (MIN) & & + & + & + \\
\hline C. longibursatus (LNG) & & + & + & + \\
\hline C. goldi (GLD) & & + & + & + \\
\hline genus Cylicotetrapedon & 2 & & & \\
\hline C. bidentatus (BID) & & + & -- & + \\
\hline C. asymetricus (ASY) & & + & -- & -- \\
\hline genus Cylicocyclus & 6 & & & \\
\hline C. radiatus (RAD) & & + & + & -- \\
\hline C. insigne (INS) & & + & + & -- \\
\hline C. elongatus (ELO) & & + & + & + \\
\hline C. leptostomus (LEP) & & + & + & + \\
\hline C. nassatus (NAS) & & + & + & + \\
\hline C. ashworthi (ASH) & & + & + & + \\
\hline genus Cylicodontophorus & 2 & & & \\
\hline C. mettami (MET) & & + & + & + \\
\hline C. bicoronatus (BIC) & & + & + & + \\
\hline genus Petrovinema & 1 & & & \\
\hline P. poculatum (POC) & & + & + & -- \\
\hline genus Poteriostomит & 1 & & & \\
\hline P. imparidentatum (IMP) & & + & -- & + \\
\hline genus Gyalocephalus & 1 & & & \\
\hline G. capitatus (CAP) & & -- & + & -- \\
\hline
\end{tabular}

$\%$ of all species recovered): C. nassatus, C. catinatum, C. goldi and C. mettami dominated in the strongylid community. Together they composed $90.2 \%$ of the total number of strongylids collected.

According to prevalence values, all strongylid species (30) were ranged in 10 prevalence classes $(0-10 \%, \ldots, 91-$ $100 \%)$. The number of taxa corresponding to each prevalence class was determined (Fig. 5).

The shape of the prevalence frequency distribution for the 64 three host species was multimodal, with no clear satellite or core modes. We propose to distinguish between four groups of species: dominant species (prevalence - $80-100$ $\%$ ), subdominant species $(66-80 \%)$, background species $(33-66 \%)$ and rare species (prevalence less than $33 \%)$.

The number of strongylid species shared by host species was determined using the presence/absence data of particular species within a host (Fig. 6).

Fourteen strongylid species (S. vulgaris, C. catinatum, 


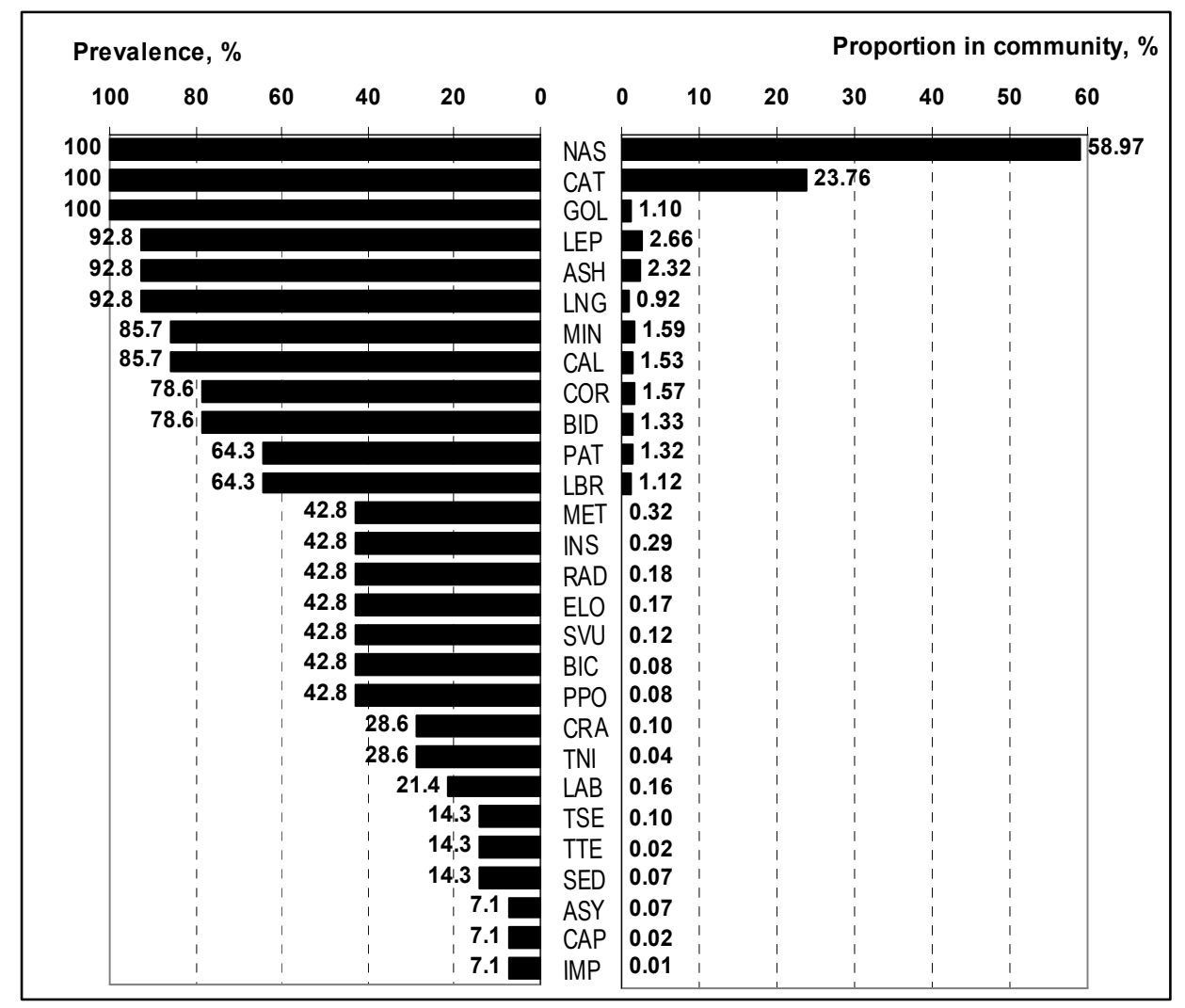

Fig. 2. Prevalence (\%) and proportion (\%) of various species in the intestinal strongylid community in ponies examined

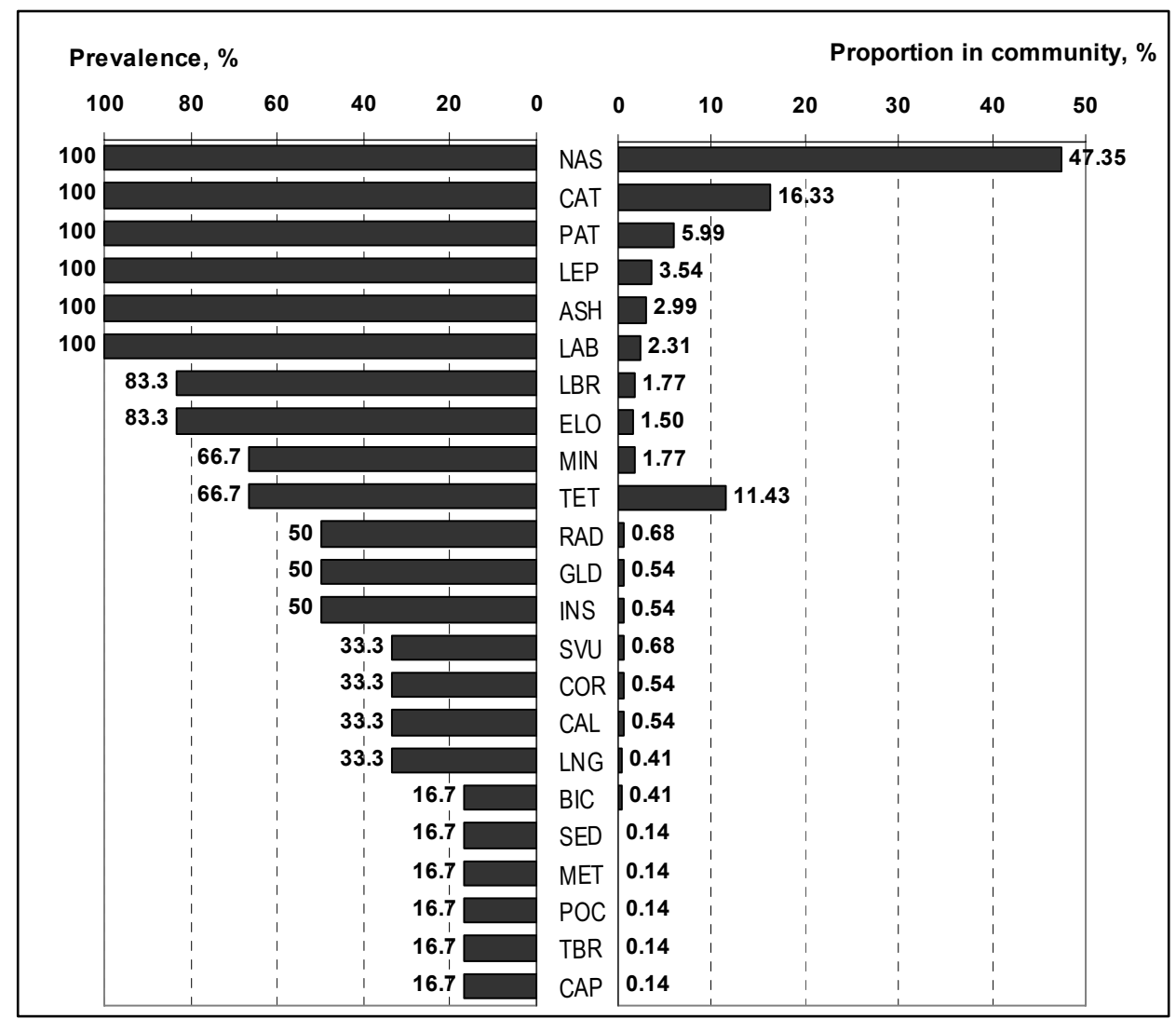

Fig. 3. Prevalence (\%) and proportion (\%) of various species in the intestinal strongylid community in donkeys examined 


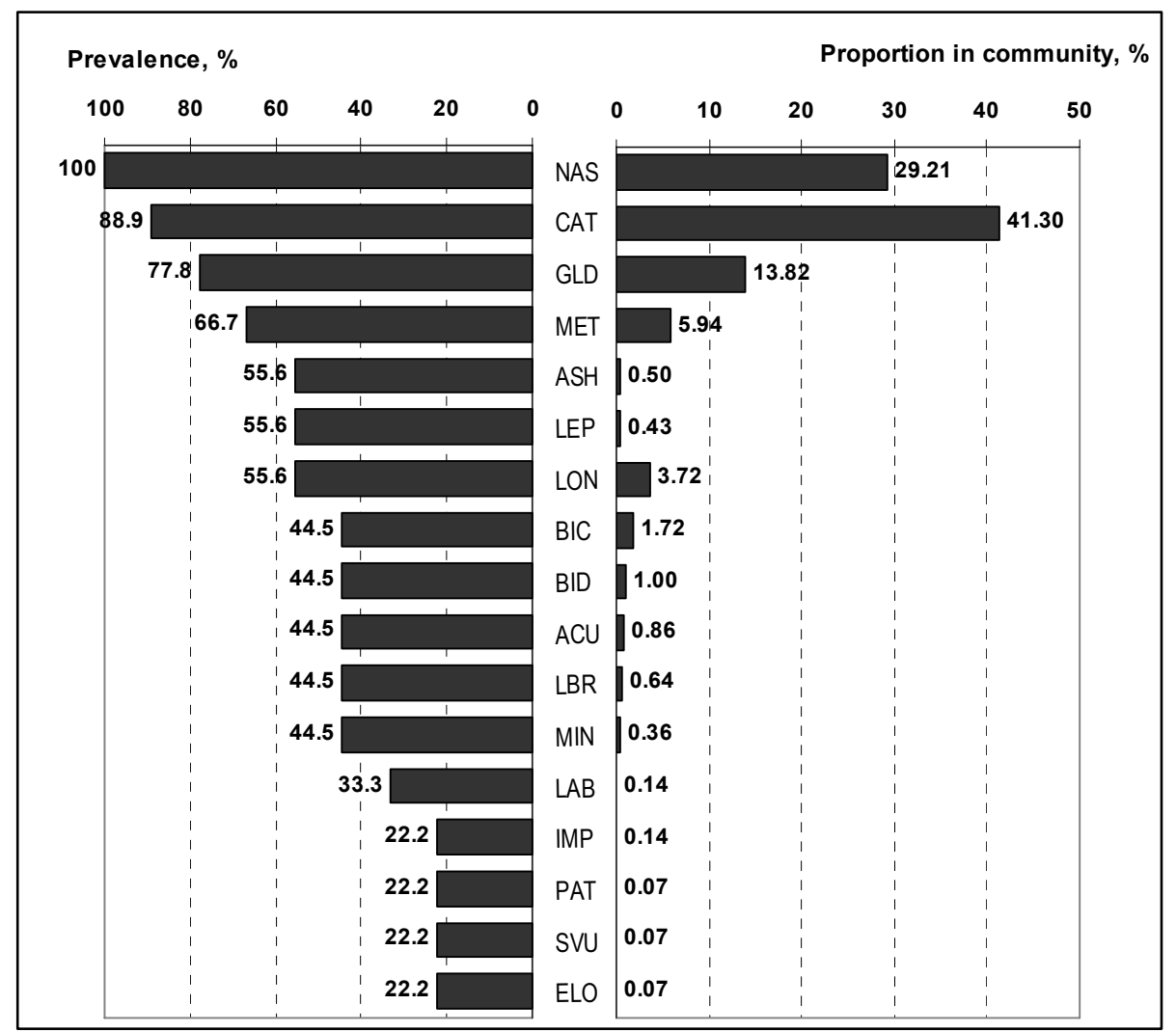

Fig. 4. Prevalence (\%) and proportion (\%) of various species in the intestinal strongylid community in zebras examined

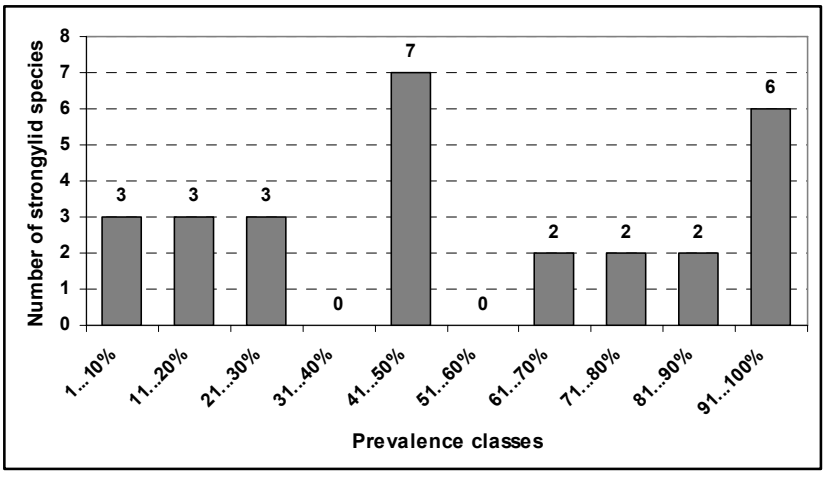

A. Ponies

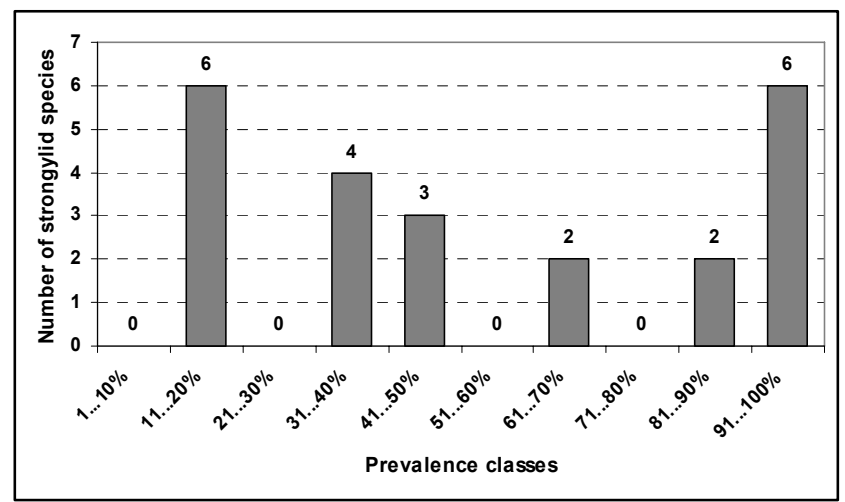

B. Donkey

Fig. 5. Number of strongylid nematodes species in ponies (A), donkeys (B) and zebras (C) from the "Askania-Nova" reserve divided into nrevalence classes
C. pateratus, C. labiatus, C. labratus, C. minutus, C. longibursatus, C. goldi, C. elongatus, C. leptostomus, C. nassatus, C. ashworthi, C. mettami, C. bicoronatus) were shared by all the equid species. Zebras shared more strongylid species with ponies (17) than with donkeys (14). Ponies and donkeys shared the largest number of species (20).

The number of unique strongylid species varied among the hosts. Four species (T. serratus, T. nipponicus, T. tenuicollis and $C$. asymetricus) were found only in ponies; three species (T. brevicauda, C. tetracanthum and G. capitatus) were found only in donkeys; no unique strongylid species were found in zebras.

The results of the multivariate analyses of the strongylid community showed the significant differences of the Shannon-Wiener diversity indices for strongylid community of donkeys comparing with communities of ponies and zebras examined (Fig. 7).

\section{Discussion}

The present work is the first comparative study of strongylid communities of three equid species conducted simultaneously during one season and in the same place. Previous comparative investigations were carried out using the material collected from animals in various regions and during several years (Dvojnos \& Kharchenko, 1994; Matthee et al., 2004). Our simultaneous study allows us to obtain representative data on the strongylid community structure that are dependent exclusively on the host species and are 


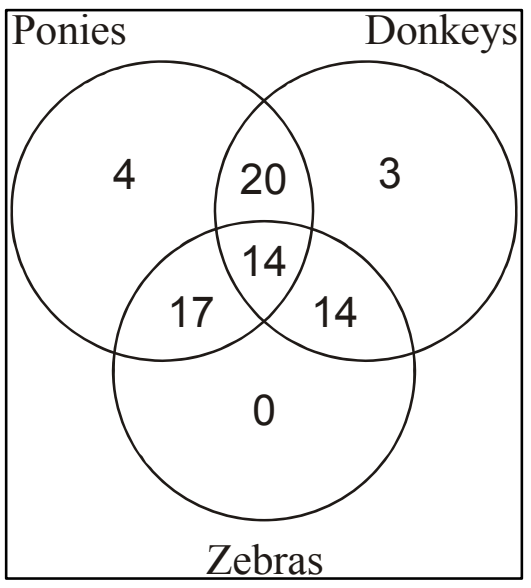

Fig. 6. Strongylid species distribution between three Equus species

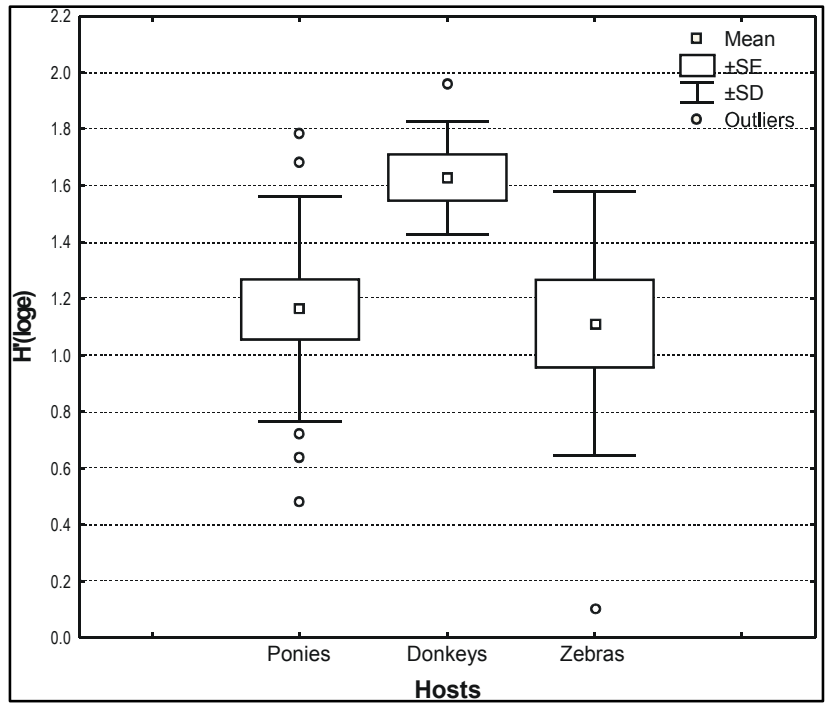

Fig. 7. Shannon-Wiener diversity indices for strongylid communities of ponies, donkeys and zebras examined

not influenced by differences in climate, geographical regions or the season.

In the present study, we need to obtain all nematode specimens from the intestine of the hosts in order to study the strongylid communities. We used the aversectin preparation "Univerm" known to have $100 \%$ efficacy against the strongylids (Yatusevich \& Sinyakov, 2005). The macrocyclic lactone anthelmintics were rarely used for equid treatments in the Askania-Nova Reserve; therefore we are almost sure that resistance to such preparations was absent in the strongylid nematodes in this reserve by the time we performed the present study. Coles et al. (2006) recommended checking of the macrocyclic lactone preparation efficacy by the faecal egg count studies on days $14^{\text {th }}-17^{\text {th }}$ after treatment. We performed the faecal egg count study on day $10^{\text {th }}$ after treatment and observed no strongylid eggs in faecal samples from zebras, ponies and don-keys. Apparently, all lumenal stages of nematodes have been expelled from the hosts examined during first days after treatment. That is why we consider that the preparation was $100 \%$ effective, at least within the scope of the present study.

Thirty strongylid species found in animals examined in the present study composed about $50 \%$ of total number of strongylid species known to parasitize equids worldwide (Dvojnos \& Kharchenko, 1994; Lichtenfels et al., 1998). Multiple strongylid infections with at least 3 species per host were recorded in all animals examined. Most species (23) belonged to the Cyathostominae, which is to be expected (Ogbourne, 1976; Renemeyer et al., 1984; Mfitilodze \& Hutchinson, 1985; Dvojnos \& Kharchenko, 1994; Gawor, 1995; Bucknell et al., 1996, etc.).

No zebra-specific strongylids from natural habitats, such as Triodontophorus burchelli, T. hartmannae, Cylicodontophorus reineckei, Cylicocyclus triramosus, C. gyalocephaloides, Cylindropharinx intermedia (Scialdo-Krecek, 1983; Krecek et al., 1987) were found in zebras in the "Askania Nova" Biosphere Reserve. Lack of specific zebras' parasites may be due to the fact that all zebras examined were born in the "Askania-Nova" reserve or were obtained from zoos. Our data may confirm the supposed existence of regional peculiarities of strongylid fauna as well as the impossibility for some species to survive and transmit under the climatic conditions of Ukraine.

The intestinal strongylid faunas in all equid species examined were similar. This is not unexpected, since all animals share the paddocks and pastures and, consequently, may share the nematode parasites. On the other hand, the specific parasites of donkeys, such as $C$. tetracanthum, were found neither in ponies and zebras, nor in Przewaski's horses and kulans studied before on the same territory (Dvojnos et al., 1990, 1992).

The species C. tetracanthum (Mehlis, 1831) Molin, 1861, in part; Looss, 1900 (=Trichonema aegyptiacum Railliet, 1923) was found for the first time in donkeys in Ukraine. Usually it is rarely found in domestic horses, with a prevalence not exceeding $20 \%$ (Collobert-Laugier et al., 2002; Dvojnos \& Kharchenko, 1994). In the study of Anjos and Rodrigues $(2003,2006)$ the species was considered as the core with prevalence up to $87.9 \%$. Usually, C. catinatum has the highest prevalence among the species of the genus Cyathostomum. However, it was not reported by the authors. In our opinion, the authors used the species names from the publication of Hartwich (1986) and did not consider the recent changes on the name of the species (International Commission on Zoological Nomenclature, 2001). The shapes of the prevalence frequency distribution of strongylid species in three hosts (pony, donkeys and zebras) were multimodal, with no clear satellite or core modes. Such a shape is common for the strongylid communities of wild donkeys and zebras (Matthee et al., 2004) and differs from the core-satellite structure of strongylid communities of domestic horses which were exposed to regular anthelmintic treatments (Bucknell et al., 1996; Kuzmina et al., 2005). Of the three equid species studied only ponies have been treated with anthelminthics at least once or twice per 
year for the last 4 years. Obviously, anthelminthic treatments can strongly affect the structure of intestine strongylid community in equids. We propose to distinguish between four groups of species in the wild equids' strongylid communities: dominant species (prevalence is from 80 to $100 \%$ ), subdominant species $(66-79 \%)$, background species $(33-66 \%)$ and rare species (prevalence less than $33 \%$ ). The strongylid species belonged to various prevalence classes varied depending on the host species; only C. nassatus and C. catinatum were dominant for all hosts studied.

The results obtained in the present study showed apparent differences in the intestinal strongylid faunas of separate equid species. Despite the fact that all equids examined graze on the same pastures, donkeys preserved their specific structure of strongylid community, and zebras lost their peculiar strongylid species.

Our results also confirm the possibility of the in vivo investigation of the intestinal strongylid communities in wild equid species as well as in domestic horses. Application of this approach allows collecting the helminthological material simultaneously from a number of animals and obtaining comparative data on the equids' intestinal parasite communities not influenced by seasons, geographical variability or human activity.

\section{Acknowledgements}

We would like to express our sincere thanks to Dr. T. Zharkikh, the "Askania-Nova" Biosphere Reserve, for her assistance in field experiments and Dr. Y. Kuzmin, the Schmalhausen Institute of Zoology NAS of Ukraine, for his valuable help in the data processing and the preparation of the manuscript.

\section{References}

AnJos, D.H.S., Rodrigues, M.L.A. (2003): Structure of the community of the Strongylidae nematodes in the dorsal colon of Equus caballus from Rio de Janeiro state - Brazil. Vet. Parasitol., 112: $109-116$

AnJos, D.H.S., RodRIGUES, M.L.A. (2006): Diversity of the infracommunities of strongylid nematodes in the ventral colon of Equus caballus from Rio de Janeiro state, Brazil. Vet. Parasitol., 136: 251 - 257

Bucknell, D. G., GASser, R. B., Beveridge, I. (1995): The prevalence and epidemiology of gastrointestinal parasites of horses in Victoria, Australia. Int. J. Parasitol., 25: $711-724$

Bucknell, D., Hoste, H., Gasser, R.B., Beveridge, I. (1996): The structure of the community of strongyloid nematodes of domestic equids. J. Helminthol., 70: 185 - 192 Clarke, K. R., Gorley, R. N. (2006): PRIMERv6: User manual/Tutorial. PRIMER-E: Plymouth

Collobert-laugier, C., Hoste, H., Sevin, C., DorCHIES, P. (2002): Prevalence, abundance and site distribution of equine small strongyles in Normandy, France. Vet, Parasitol., 110: 77 - 83
Dvojnos, G. M., KharchenKo, V. A., Zvegintsova, N. S. (1992): Characteristic of the helminth community of the Turknemian kulan (Equus hemionus). Parazilologija. 26: 246 - 251 (In Russian)

Dvojnos, G. M., KHARChEnKo, V. A. (1994): Strongylida of wild and domestic horses. Naukova Dumka, Kiev. (In Russian)

Dvojnos, G. M., Krylov, N. P., Zvegintsova, N. S. (1990): Ecological and helmintological character of the Przevalsky's horse at the Askania-Nova. The 5th meeting of the All-Union society of teriologists of the AS of the USSR. Moscow. 3: 145 - 146. (In Russian)

EYDAL, M. (1983): Gastrointestinal parasites in horses in Iceland. J. Agric. Res. Iceland., 15: 3 - 28

EYSKER, M., PANDEY, V. S. (1989): Small strongyle infections in donkeys from the Highveld in Zimbabwe. Vet. Parasitol., 30: 345 - 349

GAWOR, J. J. (1995): The prevalence and abundance of internal parasites in working horses autopsied in Poland. Vet. Parasitol., 58: 99 - 108

HARTwICH, G. (1986): Zum Strongylus tetracanthus problem und zur systematik der Cyathostominea (Nematoda: Strongyloidea). Mitteil. Zool. Mus. Berlin, 62: 61 - 102

HERD, R.P. (1992): Performing equine faecal egg counts. Vet. Med., 87: 240 - 244

INTERNATIONAL COMMISSION ON ZOOLOGICAL NOMENClATURE, O. (2001): Strongylus tetracanthus Mehlis, 1831 (currently Cyathostomum tetracanthum) and C. catinatum Looss, 1900 (Nematoda): conserved by the designation of a neotype for C. tetracanthum. Bull. Zool. Nomenclat., 58: $148-149$

KadenatsiI, A. N. (1957): The helminthofauna of the Mammalia of Crimea and the sanitation of the domestic horses from the main helmithoses. Omsk, Omsk. (In Russian)

KENNEDY, C. R., BusH, A. O. (1992): Species richness in helminth communities: the importance of multiple congeners. Parasitol., 104: 189 - 197

Kharchenko, V. A., Dvojnos, G. M., KreceK, R. C., LICHTENFELS, J. R. (1997): A redescription of Cylicocyclus triramosus (Nematoda: Strongyloidea): a parasite of the zebra, Equus burchelli antiquorum. J. Parasitol., 83: 922 926

Kharchenko, V. A., Lichtenfels, J. R., KreceK, R. C. (2001): Cyathostomum montgomeryi and its place in the Cyathostominae (Nematoda: Strongylidae). Comp. Parasitol., 68: 97 - 102

KreceK, R. C., Malan, F. S., Reinecke, R. K., DE Vos, V. (1987): Nematode parasites from Burchell's zebras in South Africa. J. Wildl. Diseas., 23: $401-411$

KreceK, R. C., REINECKE, R. K., HORAK, I. G. (1989): Internal parasites of horses on mixed grassveld and bushveld in Transvaal, Republic of South Africa. Vet. Parasitol., 34: $135-143$

KreceK, R. C., Kharchenko, V. A., Dvojnos, G. M., MALAN, F. S., KRECEK, T. E. (1997): Triodontophorus burchelli sp. n. and Triodontophorus hartmannae sp. n. (Nematoda: Strongylidae) from the Burchell's, Hartmann's, 
and Cape Mountain zebras in southern Africa. J. Helminthol. Soc. Wash., 64: 113 - 119

Kuzmina, T. A., Kharchenko, V. A., Starovir, A. I., Dvojnos, G. M. (2005): Analysis of the strongylid nematodes (Nematoda: Strongylidae) community after deworming of brood horses in Ukraine. Vet. Parasitol., 131: $283-290$

Lichtenfels, J. R., Kharchenko, V. A., KreceK, R. C., GiBBONS, L.M. (1998): An annotated checklist, by genus and species of 93 species level names for 51 recognized species of small strongyles (Nematoda: Strongyloidea: Cyathostominea) of horses, asses and zebras of the world. Vet. Parasitol., 79: 65 - 79

Lyons, E. T., Tolliver, S. C., Drudge, J. H., SwerczeK, T. W., Crowe, M. W. (1985): Prevalence of some internal parasites recovered at necropsy of thoroughbreds born in 1982 in Kentucky. Am. J. Vet. Res., 46: 679-83

Lyons, E. T., SwerczeK, T. W., TOlliver, S. C., BAIR, H. D., Drudge, J. H., EnNis, L. E. (2000): Prevalence of selected species of internal parasites in equids at necropsy in central Kentucky (1995 - 1999). Vet. Parasitol., 92: 51 62

Matthee, S., KreceK, R. C., Milne, S. A. (2000): Prevalence and biodiversity of helminthparasites in donkeys from South Africa. J. Parasitol., 86: 756 - 762

Matthee, S., KreceK, R. C., Guthrie, A. J. (2002): Effect of management interventions on the helminth parasites recovered from donkeys in South Africa. J. Parasitol., 88:
$171-179$

Matthee, S., KreceK, R. C., McGeoch, M. A. (2004): A comparison of the intestinal helminth communities of Equidae in Southern Africa. J. Parasitol., 90: 1263 - 1273

Mfitilodze, M. W., Hutchinson, G. W. (1985): The site distribution of adult strongyle parasites in the large intestines of horses in tropical Australia. Int. J. Parasitol., 15: $313-319$

OGBourne, C. P. (1976): The prevalence, relative abundance and site distribution of nematodes of the subfamily Cyathostominae in horses killed in Britain. J. Helminthol., 50: $203-214$

Reinemeyer, C. R., Smith, S. A., Gabel, A. A., Herd, R. P. (1984): The prevalence and intensity of internal parasites of horses in the USA. Vet. Parasitol., 15: $75-83$

SCIALDO-KRECEK, R. C. (1983): Studies on the parasites of zebras. Nematodes of the Burchell's zebra in the Kruger National Park. Onderst. J. Vet. Res., 50: $111-114$

SCIALDO-KRECEK, R. C., MALAN, F. S. (1984): Studies on the parasites of zebras. 4. Cylicodontophorus reineckei $\mathrm{n}$. sp. (Nematoda: Strongylidae) from the Burchell's zebra, Equus burchelli antiquorum $\mathrm{H}$. Smith, 1841 and the mountain zebra, Equus zebra hartmannae Matschie, 1898. Onders. J. Vet. Res., 51: $257-261$

YATUSEVICH, A. I., SINYAKOV, M. P. (2005): Problem of trichonematidosis in horse breeding farms of the Republic of Belarus. Vestsi Natsyanalhaj Akademii Navuk Belarusi, 2: 3 - 5. (In Russian) 